\title{
Becoming Known: A Relational Model Utilizing Gestalt and Ego State-Assisted EMDR in Treating Eating Disorders
}

\author{
Andrew Seubert \\ Clear Path Healing Arts Center, Burdett, New York
}

\begin{abstract}
Eating disorders (EDs) require a multidisciplinary approach, rather than a hammer-and-nail perspective. Based upon recent research and more than a decade of clinical experience, this article highlights the need to include a trauma-informed and dissociation-sensitive treatment of EDs. The emphasis is on EDs as a dissociative coping strategy, created in many cases to tolerate the intolerable. Ego state therapy, Gestalt principles, and empty chair technique support the adaptive information processing (AIP) of eye movement desensitization and reprocessing (EMDR) in both metabolizing painful experiences that give rise to EDs and in loosening the stranglehold of anxiety and shame. The acronym RUG-C introduces four universal principles in working with ego states: recognition, understanding, gratitude and goal setting, and collaboration. Relational ruptures between ego states/parts of the client (intrapsychic) and between the client and the world (interpersonal) are created in the client's efforts to deal with painful experiences both large and small. They are repaired in the therapeutic relationship, in the processing of past trauma, and in the rescue of body image from the power of shame. Three case reports, with transcripts, are provided to illustrate conceptualization and its application.
\end{abstract}

Keywords: eye movement desensitization and reprocessing (EMDR) therapy; Gestalt therapy; eating disorders; trauma; dissociation; body image distortion

$\mathbf{T}$ his article describes an approach to the treatment of eating disorders (EDs), which is primarily informed by the traditions of Watkins and Watkins (1997) and Perls (1969), working with clients whose ego states/parts lie somewhere in the middle of the dissociative continuum, are generally co-conscious of one another, and often are at odds. The intransigent nature of EDs, intimidating to many clinicians, loosens as the personality parts associated with, and often addicted to, an ED are contacted, become known to the client, and begin to collaborate in an atmosphere of recognition, understanding, and gratitude.

\section{Eye Movement Desensitization and Reprocessing Therapy}

Preliminary studies have shown that eye movement desensitization and reprocessing (EMDR) therapy, recognized for its efficacy in the treatment of posttraumatic stress disorder (PTSD), is also effective for many other disorders. EMDR's adaptive information processing model, posits that almost all nonorganic psychopathology has its roots in unprocessed past experiences (Shapiro, 2018). These memories are understood to continue to influence our lives by coloring our thoughts, emotions, behaviors, and perceptions. When activated or "triggered," they produce symptoms and presenting problems, causing the client to react to the present as if it were the past. EMDR therapy effectively reprocesses the memories, transforming them so that the client can perceive and respond to present situations and relationships without the emotional, cognitive, and behavioral influences of the past. The memories are not forgotten; they simply do not have the impact and influence they once did.

EMDR psychotherapy is a phase model, requiring evaluation and preparation at the start (Shapiro, 2018). Memory processing begins with the client identifying various components of the distressing memory (i.e., image, cognitions about self, emotions, body disturbance). The client then focuses on aspects of the memory for a "set" of about 30 seconds, while engaging in bilateral stimulation (BLS: eye movements, bilateral tones, or taps). Then the client is 
asked to report what she/he noticed and may report any combination of emotional, cognitive, somatic, or perceptual experiences or other memories. The therapist begins another set, asking the client to be aware of or notice reported material or any other material that may arise. This process is continued until internal disturbances reach a score of 0 on the subjective units of disturbance (SUD) scale (where $0=$ no disturbance and $10=$ worst possible disturbance), adaptive and positive beliefs are rated as valid on the validity of cognition (VOC) scale (where $1=$ completely false and $7=$ completely true), and the body scan reveals no disturbance. When relevant traumata have been metabolized, the focus is turned toward present triggers, future challenges, and integrating the new sense of self into one's daily life.

\section{Eating Disorders}

EDs such as anorexia nervosa (AN), bulimia nervosa $(\mathrm{BN})$, and binge eating disorder (BED) are serious, often chronic problems that represent a complex intertwining of biological, psychological, and interpersonal features. Consequently, successful treatment tends to require multidimensional and integrated interventions. There is, of course, the medical and nutritional course of treatment to rescue and stabilize physical health. Concomitantly, there must be psychotherapeutic attention to the mental, emotional, and relational challenges that are part and parcel of EDs. In the psychotherapeutic arena, preferred approaches to EDs have included cognitive behavioral therapy (de Jong et al., 2016; Linardon \& Brennan, 2017; Murphy, Straebler, Cooper, \& Fairburn, 2010), mindfulness (Cook-Cottone, 2016; Kristeller, Wolever, \& Sheets, 2014), dialectical behavioral therapy, and awareness and commitment therapy (Juarascio et al., 2013). Creative art- and body-based interventions have also found their way into ED treatment (Ressler, Kleinman, \& Mott, 2010).

\section{The Faces of Eating Disorders}

The feeding disorders and EDs that are of greatest relevance to this article can be summarized from the Diagnostic and Statistical Manual of Mental Disorders (5th ed.; DSM-5; American Psychiatric Association [APA], 2013) as follows:

Anorexia Nervosa. Restriction of energy intake (aka food) that results in significantly low body weight, a fear of gaining weight, and extreme concern with one's appearance, based on body size and shape. Subtypes include both restrictive (weight loss through dieting, fasting, and excessive exercise) and binge eating/purging (during the past 3 months, recurrent episodes of bingeing or purging) types. AN was the primary diagnosis for all three clients discussed in this article, typically accompanied by perfectionistic and compulsive personality traits, anxiety, and depression.

Bulimia Nervosa. Overeating compared to what most individuals would eat in a similar period of time, accompanied by a lack of control when eating. This behavior is followed by compensatory strategies to prevent weight gain (e.g., vomiting, laxatives, diuretics). This cycle must occur at least once a week for 3 months.

Binge-Eating Disorder. Binge eating at least once a week for 3 months, not followed by compensatory behaviors.

Other Specified Feeding or Eating Disorder (formerly EDNOS, now OSFED). A condition when some, but not enough, of the criteria for other EDs are present.

\section{Comorbidity: Eating Disorders and Trauma}

Recently, there has been growing attention given to epigenetics and the impact of painful experiences (aka trauma) on the etiology of EDs. It is important, however, to begin with an expanded definition of "trauma." Substance Abuse and Mental Health Services Administration (2014) offers the following definition of trauma: "Individual trauma results from an event, series of events, or set of circumstances that is experienced by an individual as physically or emotionally harmful or threatening and that has lasting adverse effects on the individual's functioning and physical, social, emotional, or spiritual well-being."

This definition has the advantage of including not only traumas of commission, which include a variety of adverse events or acts done to or against people, but also traumas of omission, which include emotional and physical neglect.

"We see the world, not as it is, but as we are" (Talmud). Trauma mediates the lens through which we see. In this article, trauma describes any painful event, large or small, that causes us to experience ourselves, others, and the world negatively through a lens of hostility, mistrust, anxiety, and intrusiveness. EDs can then, in some, but not all, instances, be considered a solution behavior, a way of avoiding unbearable experiences and feelings, and not just the source of an array of symptoms. They can be cause and effect simultaneously. 
Many authors have explored and indicated the epidemiology and influence of trauma in the development of EDs (Backholm, Isomaa, \& Birgegård, 2013; Brewerton, 2015; Utzinger et al., 2016). In his comprehensive chapter, Brewerton (2015) summarizes findings from various studies, particularly the National Women's Study $(N=4,004)$. The study found, for example, that $54 \%$ of women with a history of BN endorsed a major crime victimization experience. "Soon it became clear that the spectrum of traumatic experiences linked to EDs extended well beyond CSA [childhood sexual abuse] to include a variety of other forms of abuse and neglect" (p. 446). Backholm et al. (2013) concluded that " $\ldots$. any stressor that fits inclusion criteria for traumatic exposure may also increase the risk for developing an ED" (p. 2). This was found to be true among children, adolescents, adults, and in both genders.

\section{The Challenge: Adding Dissociation to the Mix}

In and of themselves, EDs are extremely complicated. They entail physical dangers, with AN having the highest mortality of any psychiatric disorder (Arcelus, Mitchell, Wales, \& Nielsen, 2011; Fichter \& Quadflieg, 2016). They contain an addictive aspect, which makes behavioral change all the more difficult, while providing psychological and emotional protective avoidance (Brady, 2014). Add trauma to the client presentation, particularly in its expanded definition, and we have a daunting, clinical challenge.

This challenge is further complicated by the presence of dissociation, a survival strategy that most often accompanies unresolved trauma in general, and EDs more specifically (Moulton, Newman, Power, Swanson, \& Day, 2015; Palmisano et al., 2017). A trauma-informed approach must, therefore, consider the presence of dissociation.

Dissociation, according to the DSM-5, is "characterized by a disruption of and/or discontinuity in the normal integration of consciousness, memory, identity, emotion, perception, body representation, motor control and behavior.... [It is] frequently found in the aftermath of trauma" (APA, 2013, p. 291). According to Watkins and Watkins, "dissociation exists on a continuum from mild, quotidian, and relatively harmless to extreme, unusual, and maladaptive" (Watkins \& Watkins, 1997, p. 39). The more painful the experience, the more consistent and repeated that experience, and the more absent the presence of healthy attachment, the greater the need to disconnect from the feelings, body sensations, and the self-experience generated by trauma (Seubert, 2009).

In this article, the understanding of dissociation includes (a) the personality as a "system" or "family" of related ideas and needs (Catanzaro, 2016); (b) the need for unity, cohesiveness, balance, and cooperation among parts of these systems; and (c) dissociation as a disruption of systemic functioning, particularly in the face of trauma and survival needs.

\section{Engaging the Parts: A Brief History}

As far back as the 11th century, Tibetans practiced "feeding your demons" (Allione, 2008), a collaborative approach to the undesirable and feared aspects of one's personality. Janet was perhaps the first to imply the presence of "covert personality segments" (cited in Watkins \& Watkins, 1997, p. 25). Jung, after his break with Freud, described the term "complex" as having ". . . the tendency to form a little personality of itself ..." (cited in Schwartz, 1995, p. 12).

\section{Ego State Therapy}

Federn (1952), a disciple of Freud, was the first to employ the term "ego state" to explain the dynamics of behavior. The concept of an ego state was developed into a therapeutic approach by Watkins and Watkins (1997). Ego state therapy (EST) is a way of gaining access to experiences that have been kept behind dissociative barriers and remain in need of healing. For them, "An ego state may be defined as an organized system of behavior and experience whose elements are bound together by some common principle, and which is separated from other such states by a boundary that is more or less permeable" (p. 25).

The integration of EST and EMDR in the treatment of trauma and PTSD has been described by several authors. Paulsen (1995) advised the cautious use of EMDR with dissociation, describing EMDR as having a "divining rod" capacity for dissociative barriers. Twombly (2005), Forgash and Copeley (2008), Paulsen (2009), Schmidt (2009), Knipe (2015), and Shapiro (2016) all describe procedures and strategies for successful use of ego states with EMDR. In their publications, EST is seen as giving access to, while managing, powerful and unresolved traumatic memories.

\section{Gestalt Therapy}

Fritz Perls's (1969) polarity work utilized the empty chair strategy (Polster \& Polster, 1973) to achieve integration of conflicting personality parts. The 
Gestalt assumption is that aspects (parts) of the self are out of touch with and working against each other (polarities). For example, a client may have a part that is a workaholic, which conflicts with another part that just wants to have a drink to get a break from the incessant stress of work. Both go to extremes in meeting their needs, because they are not fully known to, not fully aware of, each other. By making each other known via awareness, contact and dialogue, collaboration a greater internal harmony is achieved.

Although present-day vocabulary such as "ego states" and "parts" is typically not used in Gestalt literature, Gestalt polarity work, embodied in the "empty chair" strategy, can readily be seen as "parts work." Polster and Polster (1973) described the need for internal polarities (aka parts) to make contact with each other and end the struggle between them. Each part becomes a participant toward common goals rather than insisting that one part or the other bow out. Zinker (1978) emphasizes the importance of intrapsychic differentiation that leads to integrated behaviors. When internal parts are brought into mutual, undistorted contact through awareness, there is the possibility for integrated and cooperative behavior.

\section{Psychosynthesis}

Roberto Assagioli (2000), the founder of psychosynthesis, studied the person as a personality and a soul. Human growth, in his understanding, was the sum of ego development and peak experiences (creativity, insight, unitive experiences). He also viewed the person as made up of subpersonalities, some emulating higher values and some resisting growth and integration. The therapeutic tasks were to recognize and accept subpersonalities, bringing them to a place of coordination, integration, and synthesis.

\section{Internal Family Systems}

In more recent times, internal family systems (Schwartz, 1995) also views the client through the lens of a "full-personality multiplicity" (p. 13). Parts are organized into functional groups based on their purpose and job description. Multiplicity is respected and is not reduced to a conceptual unity. The internal system of parts is eventually guided to work together collaboratively, as would a healthy and balanced family.

\section{Theory of Structural Dissociation} of the Personality

The theory of structural dissociation of the personality (TSDP; van der Hart, Nijenhuis, \& Steele, 2006; van der Hart, Steele, Boon, \& Brown, 1993) views the self as a synthesis of behavioral and mental actions over time, action systems that are concerned with daily functioning and defense against painful events and the reminders of those events. Dissociation divides this self-process. Parts are divided into those that face the world and daily life (ANP-apparently normal part) and those that carry dissociated pain and dissociated experiences (EP-emotional part). The number and intensity of these various parts determines the level of dissociation, ranging from simple PTSD to dissociative identity disorder (DID). Therapeutic tasks include making contact with parts, overcoming various phobias (fear of the emotional parts, fear of trauma, and fear of feelings, among others), and strengthening the ANPs so as to be able to work with the EPs in the service of healing trauma and supporting integration.

\section{Treating Dissociation and Ego States in Eating Disorders}

For purposes of this article, attention will be limited to ego states or parts (not DID), terms I will use interchangeably. These states are typically mid-range dissociative, permeable to each other and to the client sitting across from the therapist. They also do not involve amnesia and are usually aware of each other's activities in the outside world (Shapiro, 2016).

Various authors have written about the presence of dissociation in EDs. A few have described the treatment of severe dissociation (DID) in clients with ED (Goulding \& Schwartz, 2002), while most have focused on work with personality "parts" (Catanzaro, 2016; Lightstone, 2004; Schwartz, 1995; Seijo, 2011, 2016; Seubert, 2009). These clinically oriented writings and presentations showed the value of "parts" work and, at times, EMDR in addressing the entrenched status of clients with EDs, illustrating how internal changes support the external work of restoring a healthy relationship to food and eating. Catanzaro (2016) described parts work with EDs from an internal family systems perspective, employing an imaginal technique of "unburdening" to metabolize the trauma. Seijo (2016) and Martin (2018) approach dissociative parts in EDs from a TSDP point of view, while also integrating EMDR in the processing of trauma. 
Seubert (2009) described an integration of EST and EMDR to treat EDs, reporting that the clients' fixated and addicted relationships to their EDs were more malleable when these were approached as dissociative parts, as parts with a purpose. The treatment model, RUG-C (Seubert, 2014), described later in this article, uses the collaboration of ego states, relational Gestalt therapy, and EMDR in the treatment of EDs. "Collaboration," rather than "integration," describes this clinical combination in treating midrange levels of dissociation (ego states). Collaboration refers both to (a) the therapeutic goal of collaboration among parts and (b) the collaborative relationship among EMDR, Gestalt, and ego state strategies, rather than an integration requiring a change in the basic nature of the parts or of the EMDR protocol.

In 2011, Seijo presented an approach that conceptualized EDs as defenses employed by dissociated parts that could be directly addressed using the TSDP model. She described one part as the "rejected self," the part that carries the shame and body image distortion. Seijo (2016) further developed her intervention, advocating for the complementary use of EMDR, the Gestalt empty chair, sensorimotor psychotherapy, and schema therapy. In early 2016, this author treated a rape victim (Seubert, 2016) whose memory was of seeing her own image in a mirror as an entity unto itself and separate from herself (see Case Example \#2). Understood as a dissociated experience, the event was approached with an EST perspective and a variation of the Gestalt empty chair, as well as with EMDR, to create contact and acceptance between the client and the girl in the mirror (GIM). This was the beginning of the GIM strategy, explained later in this article.

\section{The RUG-C Approach}

A caveat at the start: It is critical that clients with EDs not engage in trauma treatment unless they are being medically monitored and have been assessed for both body composition and metabolic rate (Hodges Chaffee \& Kahm, 2015). Additionally, complementary approaches, such as dialectical behavioral therapy and acceptance and commitment therapy groups, yoga and other body-centered practices, and creative art therapies are all part of the multidisciplinary approach required in treating EDs (Maine, Hartmann McGilley, \& Bunnell, 2010; Seubert \& Virdi, 2018).

\section{RUG-C}

The RUG-C approach (Seubert, 2014) consists of three major components or "pillars." The first pillar is the employment of EST to replace internal lack of cohesion with collaboration. The second is the use of relational Gestalt to enhance intrapsychic connections. Finally, with the internal system stabilized and connected, EMDR is then able to do what it does best, namely, to access and metabolize painful events that have either caused or contributed to the presence of EDs.

In this article, the most salient characteristics of effective approaches to dissociation and systemic re-balancing of parts, as seen in the brief history earlier, are summarized in the acronym RUG-C: recognition, understanding, gratitude and goals, and collaboration (Seubert, 2014). Rather than providing a map or categories of the interior world of the client, the RUG-C approach describes the elements or components of a relational process that is congruent, and can be utilized, with the previously described theoretical models.

\section{Recognition}

The existence of an ego state must be recognized, acknowledged, and invited into contact.

\section{Understanding}

You cannot change nor negotiate with what you do not know. Vital relationship, intrapsychic as well as interpersonal, relies on being known to each other, a knowing that leads to compassion.

\section{Gratitude and Goals}

Whatever it is that an ego state has been doing (avoiding, hiding, protecting, attacking) must be seen in the light of survival. Regardless of how negative the behavior, it has a protective intent, and that intent deserves acknowledgment. With that appreciation in place, it becomes easier to establish goals that meet the needs both of the part and the whole of the client.

\section{Collaboration}

With common goals in place, therapist, client, and client parts can begin to create a game plan (treatment plan) as to how to achieve the agreed upon goals.

\section{Relational Focus}

The RUG-C approach uses relational elements throughout all three pillars, consistent with what Clifford Smith, PhD (2017, personal communication), refers to as the process of "becoming known." First, in EST, we see the roots of a relational attitude that 
describes levels of connection (or disconnection) between client parts and the client. The more a part begins to feel connected to the client self (part of the "I," rather than a "not-I"), the more it possesses ego, or self, energy (Buber, 1971; Paulsen \& Lanius, 2009). Next, in Gestalt terminology, awareness, contact, and dialogue are understood to create connection and reduce dissociation. Tobin (2004) sees classical Gestalt strategies, such as the empty chair, creating dialogue among parts, and emphasizing process rather than content, as an effective fit with EMDR, which then solidifies that which emerges from Gestalt work. Finally, EMDR may be most effective when seen "as a two-person therapy; that is, a therapy that employs dialogue between clinician and client about the resonance, attunement, and intention of their relationship" (Dworkin \& Errebo, 2010, p. 114).

\section{EMDR and Ego State Therapy}

Some ego states contain the painful memories, others protect against the pain, and some do both. A major premise, learned during my Gestalt years, is that one thing always follows another, so follow what is given. Much of this following and getting to know various parts takes place during the preparation phase of treatment. This is when we develop new goals and the plan to reach these goals, which now includes the desensitization of past trauma, present triggers, and future challenges.

Engaging With Ego States: Before, During, and After EMDR Processing

Before desensitizing the memory of a past event with a specific part, preparation focuses on the steps in RUG-C, strengthening internal stability and harmony. Parts containing the memories are encouraged, supported, and given psychoeducation about trauma and the negative story it creates. Parts that protect are asked now to help with healing, rather than hiding. Parts that dissociate are taught to stay present and are given resources (both internal and external), if needed, to accomplish this.

With all of this in place, ego states are addressed before, during, and after EMDR processing. Before beginning trauma processing, relevant parts are asked if they need anything and are reminded that they are being fully supported and have the power to stop the processing anytime they feel it necessary. They are also instructed to be part of the processing by staying close and present during BLS. If, during the processing, there is a block or looping, an ego state strategy is to directly ask, "I'd like to speak with the part that is having a hard time." This is an ego state interweave, one that directly connects with the source of the interruption. Finally, after processing, the relevant ego states are contacted to make sure they are well, that they know what to do in between sessions, to celebrate success, and eventually to begin the integration of the new identity into daily life.

\section{Strategies and Techniques}

\section{The Conference Room Technique}

A major goal of preparing a client for ego state therapy is to get to know the system of parts. The conference room strategy has its roots in Fraser's "Dissociative Table Technique" (Fraser, 2003), an imaginal meeting place that is safe and secure and where client and parts can become known to each other. "Meeting Place" might be a more appropriate term, as it does not limit the client's imagination to an indoor space.

\section{Gestalt Empty Chair Strategy}

The intent of the Gestalt empty chair strategy (polarity work) is for the client to become each part of the dialogue and to successively speak and listen as each of those parts, ideally creating more transparency, understanding, and mutual compassion (Polster \& Polster, 1973). This also leads to a greater sense of mutual "I-ness," reducing the dissociated "otherness"(Buber, 1971). Here are the steps in the procedure that support a dialogue between client and part, as well as among various parts:

1. Client (in one chair-Part "A," which could be either the adult client consciousness or one of the parts) is asked to tell the other part (" $\mathrm{B}$ "- - in another chair) what A wants part B to understand about him/her. The more transparent each participant in the dialogue is willing to be, the better. Transparency reduces the need to either defend or attack.

2. When A is finished, client is asked to sit in B's chair and become that part. Therapist summarizes what A said and communicates it to the B part, so that the client, now as B, can take in what was said by $A$.

3. Then the therapist asks $B$ to speak to $A$, and let $A$ know what she/he wants $B$ to most understand about him/her.

4. Client is then asked to return to the A chair and A consciousness, and listen to the therapist summarize what B just said.

5. This process is repeated until both $A$ and $B$ are more known to each other, reaching greater understanding, compassion, and, hopefully, cooperation. 


\section{Girl in the Mirror}

A recently added strategy to the RUG-C interventions is an adaptation of the empty chair technique. Body distortion is an integral component in EDs, and clients often struggle with their own self-perception (Stern, 2010). One of the more intransigent and deeply rooted aspects of EDs is the body image distortion (Martz \& Rogers, 2016). In the past, this condition has been treated primarily with various approaches within the CBT tradition (Cash, 2008). More recently, treatment has begun to focus on "bottom up" approaches such as body awareness, movement, and yoga, as well as greater use of creative art therapies (Ressler et al., 2010).

As mentioned previously, another theoretical perspective is to view the distorted body image as a dissociated part of the personality, the part that carries shame (Seijo, 2011, 2016). The GIM strategy (Seubert, 2016) unfolded while processing a college rape memory with "Cassie" (Case Example \#2) and was then developed into a simple and comprehensive technique. The GIM approach incorporates elements of EST, Gestalt therapy, the empty chair technique, and EMDR therapy.

The GIM technique asks clients to imagine seeing themselves in a mirror and to enter dialogue with the image, understood as a "part." For clients with EDs, the image in the mirror presents as an external, dissociated projection of a shame-based egostate. This strategy is also useful in tracking progress in the processing of shame-based traumas, such as rape and molestation (see Case Examples \#2 and \#3). This is performed by using the image as a pre- and post-check on the status of a client's shame base.

\section{Case Example \# 1: RUG-C and Attachment Repair in a Client With Anorexia Nervosa}

"JB" was referred and monitored by the Upstate New York Eating Disorder Services. Diagnosed with AN and concomitant anxiety and depression, she was a married, stay-at-home mother, with two young boys, aged 11 and 8 years, and a passion for fitness and participating in half triathlons. At the time of the referral, she had already been through several inpatient facilities to restore her weight, only to succumb to panic, anxiety, and her ED whenever she began to gain weight or felt bloated due to menses or menopause.

JB was the middle of three children, with an older sister and younger brother. Her father was of Iranian descent, very anxiously protective of his children, particularly his daughters. Her mother was from Germany, and very responsible and reliable, but lacking warmth and nurturing. Her mother also displayed a great deal of anxiety. JB described her parents as quite controlling, leaving her with a sense of living in "one box after another," always needing to get approval from others, rather than being able to generate a sense of efficacy from within. She stated that her ED started when her siblings began teasing her about her weight at the age of 7 .

History taking focused on events both large and small that might have given rise, or at least contributed, to her ED. JB described an event at age 3, while visiting her mother's relatives in Germany, when her mother announced that she would be traveling back to the states ahead of the rest of the family. The image JB recalled was of her wrapping her arms around her mother's legs, crying, afraid her mother would leave her in Germany. This raised questions regarding the security of her attachment to her mother. Other memories concerning her overly controlling parents and weight fears were added to the list as well as her disclosure of being fondled by a speech teacher in third grade.

\section{Stuck at the Start: Evolution of an Integration}

After history taking and preparation (awareness, breathing, affect management, ability to state change, and containment), we (author and client) processed the earliest memory of being left behind in Germany. The incident was cleared successfully, and, since there appeared to be no other early painful memories, we began to work on the first memory at 7 of being teased about her weight.

Pillar I: Ego States and the Uncovering of Attachment Wounds

JB began to process the memory of being teased about her weight by her siblings, but ran into an impasse. This happened after only several sets of EMs, when JB suddenly exclaimed, "I can't feel anything! It's like a wall just went up. . ." Although very capable of feeling her emotions, she could feel nothing about this memory. Two things were clear: (a) that there was very little sense of "self," which encouraged me to return to history taking and obtain a more detailed attachment history and (b) that something of a dissociated nature was getting in the way.

A return to history taking revealed that her older sister had been born in Germany, but that JB was born in the United States. Her mother did not want to bear a child in this country and was depressed during the entire pregnancy and then had been unable to 
breastfeed JB because she "had no milk." JB began the next session by announcing, "There's one thing you need to know about me. If I ever feel happy, that will make me fat!" At that point, it was clear not only that attachment repair needed to be addressed, but that dissociated parts would also have to be engaged. JB was too intelligent a woman to fully believe that feeling happy would create weight gain. The statement was the thought process of a very young child. When there is evidence of dissociated parts, the first task is to get to know the system.

Since the most important relationship to be nurtured is that of client to part(s), most questions for the ego state were directed through JB, although there are times when direct dialogue between therapist and part is not only advantageous, but even necessary (as when the client is either afraid or ashamed of a part, or when a part does not trust the client self). JB was asked to imagistically create an internal conference room, and then to imagine herself entering it.

A: JB, I'd like you to invite into the room the part or parts that believe that feeling happy will make it fat [Recognition]

JB: Okay. They're there.

Andrew: Can you describe them? And about how old do they seem?

JB: There are two, about 6 years old. One is the Claw and one is the Blob. (Note: There is no placing of names or labels on parts unless that information is given.)

A: Would you ask them what it is that they most want us to know about them? [Understanding]

JB: Well, the Claw probably started out wanting to protect me, but then, then it wouldn't let me feel happiness, because it would just be taken away. And, and if I don't feel it, it can't be taken away.

A: Nothing to lose. ...

JB: Right. ... And the Blob protects me from keeping anything bad from happening, and it does that by controlling, uh, everything around me ... and everything is out of control.

A: So, let me get this right. If you're not allowed to be happy, you'll never be disappointed, and if you can be in control of a lot of these small things in your life, that will keep bad things from happening?

JB: Uh, huh.

A: And if you ever feel happy, bad things could happen, because you could be disappointed and hurt.

JB: (slight smile, nods)
A: Are they tired of those jobs? [Goals]

JB: I think so . . because they want help.

We proceeded to establish the common goal of freedom from pain and disappointment. It was what JB, her parts, and I all wanted. Yet the older strategy, established around the age of 7, was no longer working. We had to find a way to handle and release pain for good, but now with new skills and through the metabolizing of painful events (Collaboration). The Claw, Blob, and later, "7," agreed to work toward that goal by learning to tolerate and manage emotions and neutralizing the impact of being teased at age 7 .

But it was not to be that easy. Some part(s) were blocking any progress.

Further Exploration of Ego States. In addition to the Claw and the Blob, there were other ego states who were strongly attached to the ED and were committed to the blocking of painful emotions, particularly shame. Anger and anxiety stood in the foreground of JB's awareness; shame festered in the background. Through the conference room, we discovered, among others, a 10-year-old part and a teenage part. Since no names were given, they were referred to as " 10 " and "teenager."

One evening at the dinner table when she was around 10, JB had asked her mother if her mother thought she was fat. Her mother replied, "Oh, you're fine ... but, maybe you could lose a few pounds." These words were tantamount to an emotional dagger, creating a wound that remained open decades later. But the most oppositional and the angriest of the ego states was "teenager." The teenager part (TP) blamed " 7 " and " 10 " for her anger and unhappiness. "If they (7 and 10) weren't fat, then I wouldn't have to starve myself. But now, it's either I starve or I get fat."

The fear of fat had permeated much of JB's inner world. Approaching this internal impasse cognitively or purely behaviorally might be necessary, but clearly insufficient. The blockage was outside of consciousness, and the logic was that of a scared child. It is at the developmental level of the impasse that much of the work must take place. Instead of working together to expose the great lie of being "fat and disgusting," JB's parts either blamed each other or accepted blame. They totally believed they were innately disgusting and powerless, and the only way out was weight control.

Before healing, there needed to be cooperation, which previously had been absent. Using the RUG-C framework, TP was approached with the hope of establishing new goals and collaboration, including withholding blame and not interfering when we 
returned to the EMDR processing with " 7 " and, later, "10." What all parts came to realize was that when one or several parts healed, that the healing had a ripple effect on many others in the system.

\section{Pillar II: Relational Gestalt, the Empty Chair, and RUG-C}

TP, "10," and JB herself all tended to blame " 7 " for their pain. Before negotiating with TP individually, we explored the blaming patterns systemically with hopes of reducing the need to blame. During one session, when JB found out that she had gained two pounds, the internal conflict and lack of collaboration among parts, and between parts and JB, was dramatic. I employed an extended form of the empty chair strategy, setting up physical chairs in my office as various parts emerged in the dialogue. The first was a 10- to 13 -year-old part ("10"), then the teenager (TC), and finally JB herself. JB was asked to sit in different chairs as each part revealed itself via shifting emotional states. The hope was for JB and her parts to get to know each other, using the previously described Gestalt empty chair strategy.

JB: I'm so disgusted with myself! I'm so ashamed, 'cause I'm so fat now.

A: So what brings this on?

JB: I gained weight. I'm fat, and I'm disgusting. And I don't have any other choices. Either I get fat or I starve [JB clearly absorbed or lost in a younger "part"].

A: Sounds like a rock and a hard place.

JB: Exactly. I'm just so tired of feeling so crumby about myself. [Tears, release follow; therapist senses the presence of a reactive "part."]

A: Would you be willing to try something? (she nods) I'd like you to really pay attention to how disgusted and ashamed you feel ... What else are you noticing?

JB: I'm sad, so sad. No one knows how hard this is or how awful I feel.

A: When you feel this sad, and disgusting and ashamed, how old do you feel?

JB: Anywhere between 10 and 13 .

A: Is there anything you would like me to know about you [therapist now directly addressing the younger part]?

JB: Just that no one knows how hard this is for me.

A: Do you have anyone to talk to?

JB: (shakes her head) [More tears ... then affect subsides].
A: Would you be willing to try something else? (nods) I'd like you to sit somewhere else [bringing JB back to her adult state]. Now from this place, I'd like you [JB] to look over to $10 / 13$, and is there anything you'd like to say to her, now that you've heard how sad and disgusted she feels? [Dialogue continues to take place directly with parts. The chair strategy creates a necessary separation between JB and part. Otherwise, we have a part taking over the whole of the client.]

JB: I just hate her. She's fat, and I just had to take over [anger apparent].

A: And not eat?

JB: Yeah. She's made my life miserable. Now I have to starve or I become like her [anger increasing].

A: [sensing the presence of a different part and different affective state] And how old are you now?

JB: Oh, older teen. And now I only have two choices: be fat or give in to the eating disorder.

A: If there were another possibility, would you be interested in hearing about it?

JB: Yeah.

A: Okay, now I'd like you to move back to the chair for 10 and slip back into that 10 -year-old place. There yet?

JB: Yes.

A: So how was it to hear what the older teen had to say?

JB: [10] I think I deserve it.

A: Well, I'd like you to hear something. ... [in age appropriate language, I explain the need for weight gain during certain developmental stages]

JB: I wish I could believe that.

A: So now return to the older teen (changes seats). How was it for you to hear how it is for 10 ?

JB: [Teen speaks] I still hate her. She's making my life miserable. But, but then (more tears), as an adult (JB shifts spontaneously to adult consciousness), I just know that if I gain weight, I become her (pointing to 10's chair).

A: Okay, would you sit in the adult chair? (she moves again to a third chair) Say more, JB, about what all this is like for you.

JB: I . . I [ the adult] don't like her [10] either.

Although not the outcome hoped for, the internal blame and impasse were at least made conscious, and contact began between parts and 
JB. This was the beginning of a long road toward internal understanding and compassion, the recognition and understanding components of RUG-C. Further dialogue between myself and the teenager via JB in the conference room led to the beginning of creating mutual goals and developing ways of collaborating. In another session, the angry, blaming teenage part (TC) wanted to express her position.

TC: I don't like her [referring to "10"]. I have all this pain, because she's fat!

A: [through JB, who then relays TC's answers to A]: I wonder what it's like for 10 [also present in the conference room] to hear this....

10: I just have to take it. It is my fault.

A: [to JB]: It strikes me that they both share the same pain [fear and shame] and that they both want the same thing.

JB: Yeah [grudgingly]. They don't ever want to be in that position of being teased again. If they control everything, they'll never be able to be hurt like that again.

A: [to JB, but aware that TC and 10 are listening]: It's important for each of them to know that each of them carries the same pain, and that they both have the same goalfreedom from that pain. As do "7", Claw, and Blob.

A: [now addressing TC directly]: TC, if you try to control the body out of a fear of that pain, you'll never be happy ... and we are less susceptible to that kind of pain the more we stop believing somebody else's story about us.

JB [nods slowly]: TC is skeptical. The rest are . . . uh, hopeful.

A: Skepticism is not a bad thing. If TC sees progress being made, perhaps she could in some way be supportive. Then everyone else can give her the support she needs . . . to be free.

JB: [once again, nods]

Through ego state dialogue and elements of a relational Gestalt empty chair strategy (awareness and experience in the present moment, dialogue, becoming known), parts of JB who had been operating unconsciously and without much choice began to make contact with each other and with JB. As this internal cohesiveness increased, attachment repair became achievable. This repair was a goal in and of itself, as well as necessary groundwork for healing the 7-year-old memory of being teased.
Pillar III: EMDR—Healing Attachment, Healing the Pain

Attachment Repair. The 7-year-old part of JB had very little sense of self, due largely to a shaky attachment experience at birth and during the first year or two of her life. For one, her mother, German by birth, did not want to give birth in this country and, secondly, was unable to produce milk for the infant JB. We agreed that there needed to be a corrective experience at this pre-verbal level, with the hope that positive outcomes would generalize, reaching and strengthening the self of 7 .

The "newborn" part of JB needed to be expected and welcomed into the world. JB, who knew well how to parent, was asked to imagine herself going back in time to imaginally deliver to the newborn JB what the baby needed. This is a process I simply call "reparenting," which can be found in various manifestations in several other authors (O'Shea \& Paulsen, 2015; Schmidt, 2009; Steele, 2007). EMDR was not employed, so as not to inadvertently trigger association to anything negative.

We briefly discussed what any newborn would need. JB was guided to return in time to her own birth and to take the baby from her mother's womb upon delivery. She imaginally wrapped the infant in a warm blanket, rocked, and fed her. She shed many tears during those positive moments, an experience (Smith, 1989-1992) described as the "pain of touch" and can be understood as "sweet sorrow" (Seubert, 2008). In the moment she experienced something so precious, she also realized how long she had been without it. It is a bitter and sweet experience. We ended this segment by bringing the infant forward in time to be with JB (Pace, 2005).

Having done this successfully in my office, JB was assigned daily nurturing time with her newborn "part." As Steele (2007) is fond of saying, "Talk to the child!" After success with this repair, we were ready to move on to the next attachment piece, the absence of a mother's nurturing milk.

For this part of the repair work I employed EMDR, since JB's imagination immediately conjured up a specific image of herself, as an infant, finding no milk in her mother's breast. When asked for any negative belief about herself that connected to that image (the negative cognition), she replied, "I'm a burden!"

We proceeded with the standard EMDR protocol. The guilt and shame that accompanied the sense of being a burden gradually dissipated, as did the tears and the somatic disturbances. Eventually, she looked over to me after one of the final sets of EMs and said, 
"Wow! That was just mom!” It was no longer about JB.

The attachment repair process often requires resources to support the client in this emotionally poignant work. By definition, a resource can be a memory, a person, spiritual being, or pet-anyone or anything that the client recalls as positive support or reinforcement. Although JB could re-parent without external resourcing, it should be noted that it all took place within the context of a strong and trusting bond that had been established between us. The therapeutic relationship is, perhaps, the ultimate resource for the client.

After almost a year's work of RUG-C and attachment repair, JB was ready to return to 7 and the memory of being teased by her siblings.

\section{Reprocessing 7's Memory}

After almost a year not only of attachment repair, but also of occasional exacerbation of ED symptoms, family crises, job difficulties, and lack of support, we were ready to free 7 . There was now an improved sense of self, given the repair that had been done, but 7 was heavily burdened with a sense of shame, such that it took three EMDR sessions to completely metabolize the one memory.

The initial image of the worst moment was that of her siblings taunting her and the recollection of what they were saying, "Fat, fatty, JB's fat!” Her global negative belief was "I'm fat and disgusting." Since the shame was still so intense, we titrated the memory, processing it for about 15-20 minutes at a time, returning to the processing at the next session. This gave her innate healing system the opportunity to metabolize some of the shame organically in between sessions.

At the start of each session, JB was asked to check in with 7, to make sure 7 was alright and to see if 7 had any particular need. Resourcing was in place, particularly since JB's relationship to 7 had healed, and JB had learned to embrace 7 , rather than blame her.

A: JB, would you check in with 7 to see how she is before we begin?

JB: Sure . . . [tears flow] . . she's, she's good. 7 says she's alright! [strong release followed]

JB was finally coming home to herself. The session continued and completely cleared any remaining disturbance from the memory. 7 had become relationally healed and strengthened through ego state work, paving the way for EMDR to erase the memory's impact.
I asked JB what it all felt like.

JB: It's like a lightness. [Brushing her shoulders with her hands a few times ... .] Like a burden has been lifted. It's like, like . . . free.

Memories, due to the associative nature of the brain and, therefore, memory storage, often contain a level of disturbance that is greater than one would expect. Although it took us the better part of a year to be ready for this memory and three EMDR sessions to complete it, the work with 7 was a significant breakthrough, particularly since the shame surrounding the memory, as well as associated shame, had been in place for approximately four decades.

JB was ready to heal " $10 . "$

Healing "10" With Ego State Therapy, Spontaneous Gestalt, and EMDR

The next event we chose to process was JB's memory at age 10 of her mother telling her that she "could do to lose a few pounds." Yet her mother told her she looked fine. This created confusion and heightened her own inability to realistically assess her own body status.

As usual, we began by having an ego state dialogue with 10 (before EMDR), clarifying what 10 wanted to achieve-confidence in her own body self-assessment by not relying on the story someone else tells about her. JB agreed to provide re-parenting (ego state resourcing) for 10 before proceeding with the memory processing. This turned out to be more complicated than expected.

When asked to return to the past to support and nurture 10, JB realized that she couldn't do it alone. She felt that her own perception of 10 was "tainted." She couldn't help but see 10, to some extent, through a lens of shame. She needed an external resource.

JB's grandmother had been her only source of nurturing and caring growing up. Unfortunately, she had died several weeks earlier, and JB had no other resource she could think of or want. Although grief would be intermingled, JB chose to return to the past to 10 with her grandmother. As JB imaginally experienced her and her grandmother approach 10 , the affect storm swelled. JB was feeling what 10 was feeling, was becoming enmeshed with 10 and losing her adult consciousness, particularly as she recalled how her grandmother would hug her. 
JB: I just remember how she hugged me [sobbing]. She just wrapped me up ... and it felt so good.

The options were to either pull back from the emotional experience or dive into it. JB chose the latter, effectively initiating a spontaneous "empty chair" experience by stepping into 10's experience.

A: JB [addressing the adult], would you be willing to let go and be 10 ? And take in that hug for as long as you need? I'll make sure to keep contact with you.

JB: Okay.

Tears and more sobs began to wash away some of the emptiness and loneliness that filled much of JB's childhood. At this point, EMDR, in the form of gentle tapping on the sides of her knees (Steele, 2007), was utilized until the storm began to subside.

A: JB, I'd like to speak with you now. Do you feel more like 10 or the adult?

JB: Like ... like 10.

A: We're going to begin to bring this experience to a close if that's alright with you ... [she nods], but I'll need to bring the adult more forward. Can you begin to focus on your two sons, how you parent them? And your husband? [she takes in the suggestions and nods again] Good ... Now I'd like you to take leave of 10, letting her know that you'll be in touch with her on a daily basis ... and then begin the journey back up through the years...

As JB was quite exhausted after that experience, we closed the session, agreeing to proceed with the memory processing in the next session.

When she returned, we checked in with 10 (before $E M D R)$ who felt supported and was ready to work. Her negative cognition was "I'm fat and disgusting." Her positive cognition was "I'm okay and healthy." Since resourcing and grief processing had already taken place, the desensitization went smoothly, without any need to address 10 during the processing, and the positive cognition felt completely true.

A: JB, now that you have that memory behind you, how is 10 ?

JB: She's really okay ... and she knows that was just mom. It was her stuff!

In this session, all three of the "pillars" of this approach came together. The 10-year old part was addressed before processing, leaving no need for an ego state intervention during the desensitization phase.
After the processing, as well as at the beginning of the following session, JB checked in with 10 to make sure all of 10 's needs had been met. Finally, in the middle of the re-parenting experience, a spontaneous Gestalt polarity experience took place, which enabled JB to perceive 10 no longer as "tainted" or disgusting but as deeply hurt and alone.

We proceeded with the desensitization of other painful memories and present-day triggers, enlisting various ego states in support of each other. JB's work continues, particularly with regular visits to a nutrition clinic, to make sure that her food intake matches her energy expenditure. She became a personal fitness trainer and continues to pursue her passion for mountain biking and half-triathlons. What enables her to tolerate higher levels of food intake is the fact that she no longer carries the identity of "fat and disgusting." There have been no hospitalizations and no need for therapy since she ended treatment 3 years ago.

\section{Case Example \#2: Ego States, Gestalt, EMDR, and the Girl in the Mirror}

"Cassie" had been referred by the Upstate New York Eating Disorder Services, due to her cycling between $\mathrm{AN}$ and BED, purging type. In her mid-twenties, she described growing up with an explosively angry father and a passive mother. She never dared to have a voice and always tended to second-guess herself and her own worth. In grade school, she had been bullied and teased about her weight. In pre-adolescence, she had been sexually abused by a cousin. We spent a good number of sessions repairing attachment wounds, resulting from experiences with her parents, as well as from numerous bullying incidents. She chose to leave the worst for last, namely her sexual relationship in college. The boyfriend would often posture in front of his friends by ridiculing her looks and her body in front of them, then proceed to get drunk and rape her.

In the memory being processed, Cassie was in her college dorm, just having experienced what she later realized was rape by her boyfriend. During the processing, everything came to a screeching halt. Cassie recalled seeing herself in a mirror after being raped and was appalled at what she saw.

The image in the mirror was huge, grotesque, and had appendage-like growths hanging all over her body. The image was so powerful that Cassie exclaimed:

C: My god! That image ... it's me, and it's like in the room, like a presence. I hate it! 
Clinically speaking, the moment was confusing. Was this a psychotic or hallucinatory feature presenting itself? Yet in the months we had worked together, Cassie had never revealed such tendencies. During a consultation with Sandra Paulsen months earlier (2014, personal communication) concerning another client suffering from DID who heard "voices" outside of her, Dr. Paulsen suggested asking to have a conversation with the voices. If possible, then the condition was most likely dissociative, rather than psychotic.

Cassie was asked to address the presence she had described. The conversation began, effectively a variation of the empty chair, employing the elements of RUG-C.

A: Cassie, can you ask her [the image in the mirror] what she wants you to most understand about her?

C: She says she's so hurt and so lonely ... but I don't like her. I feel kind of cold towards her.

A: Ask her if there's anything more.

C: She says that every time she was bullied in school, another one of those things hanging from her body appeared. And it got so bad with my boyfriend. She just hates herself.

A: And what's that like for you, Cassie?

C: [beginning to tear up] I'm starting to hate what happened to her. She didn't deserve any of it ... [Pauses to breathe. More tears.] I just want her to stop hurting.

A: Could you ask her how it feels to her to hear you say that?

C: She says she's waited so long to hear that ...

Shortly after that dialogue, we returned to the processing, no longer stuck, and proceeded to the conclusion of the desensitization, the installation of the positive cognition, and the body scan. Cassie was guided to return to the memory, to the dorm room, and to the GIM.

A: Cassie, could you tell me what you see in the mirror now?

C: Hm-m, it's different. Some of those append-

ages have fallen off. Some are still falling off.

And she's not so big...

The image in the mirror, apparently an external, dissociated projection of a shame-based ego state, had changed immediately after processing the shaming, rape experience. The image could now be used as a pre- and post-check on the status of Cassie's shamebased trauma.

\section{Case Example \#3: Ego States, Gestalt, EMDR, and the Girl in the Mirror}

"Vanessa" was a 17-year-old girl, receiving treatment for an ED and past trauma. She had been fondled by neighborhood boys when she was 12 and had struggled with her body image ever since. An ongoing element of our treatment had been the use of the girl in the mirror technique.

At the start of one session, she informed me that, while on a class trip the previous week, a boy, supposedly a good friend, had fondled her as they sat together on the bus. She agreed to process the memory. I invited her to bring up the image of herself in the mirror, now in the immediate aftermath of the recent fondling.

A: Vanessa, would you look into the mirror and tell me what the girl in the mirror looks like?

V: She's a lot bigger now. She's not standing. She's sitting and curled into a ball. People are all around her and screaming at her, and she has even more cuts on her legs. The bugs are still all around her and she still has yellow, crooked teeth, and acne. Her glasses are broken now and tears are all over her face.

A: And what would you like to tell her?

V: I wish she didn't have to go through that. . .

[Recognition and Understanding].

Using the Gestalt chair technique, I asked Vanessa to become the GIM.

A: What was it like to hear that from Vanessa?

And what do you most need?

GIM: I felt really, really good ... and I so want to

not be forgotten any more.

We proceeded to process the recent memory successfully. Afterwards, I asked her to look at the girl in the mirror once more.

$\mathrm{V}$ : Well, the bugs aren't there, and there aren't as many people. But the cuts are still there ....

A: So, things are still there, but it's better?

$\mathrm{V}$ : Yes, it's better.

\section{Discussion}

To reiterate an earlier statement, EDs are complex and require a multidisciplinary approach. This article offers a trauma- and dissociation-sensitive approach, one in which EST, Gestalt therapy, and EMDR have been applied to the treatment of EDs. The RUG-C approach integrates all three in the treatment of EDs from a trauma-informed perspective. 
A primary aspect of this approach is the researchbased knowledge that trauma, writ both large and small, often accompanies EDs. Given that dissociation is a common strategy in coping with trauma, clinical experience indicates that EDs contain, to one extent or another, elements of dissociation. EDs, in fact, can be understood as dissociative strategies in and of themselves, viewed from an ego state tradition as "parts." A Gestalt relational approach stresses the need for parts and the client to dialogue and to become known to each other, working collaboratively toward trauma healing. Consequently, in the healing of past painful events and the negative self-story they engender with all three pillars of this approach, the need for the EDs, as protective and compensatory, diminishes.

Research now reveals that trauma and concomitant dissociation are often present in the profile of clients with EDs (Backholm et al., 2013; Brewerton, 2015; Utzinger et al., 2016). Publications describing treatment approaches to this comorbidity have appeared during this past decade (Catanzaro, 2016; Goulding \& Schwartz, 2002; Lightstone, 2004; Schwartz, 1995; Seijo, 2016), some specifically employing EMDR (Forgash \& Copeley, 2008; Knipe, 2015; Paulsen, 2009; Seubert, 2009; Twombly, 2005). Authors from various theoretical traditions (EMDR, CBT, somatic experiencing, somatosensory psychotherapy, among others) have recently described their treatment of comorbid trauma, dissociation, and EDs (Seubert \& Virdi, 2018).

Further research, however, is required to demonstrate the general effectiveness of a trauma- and dissociation-informed approach to EDs, possibly comparing various models of dissociation and trauma treatment, one with the other. Finally, comparing approaches that include a trauma/dissociation perspective with those that do not would certainly be of interest and a help to clinicians working with clients who have developed ED pathologies as a means of tolerating the intolerable.

\section{References}

Allione, T. (2008). Feeding your demons. New York, NY: Little, Brown \& Co.

American Psychiatric Association. (2013). Diagnostic and statistical manual of mental disorders (5th ed.). Washington, DC: Author.

Arcelus, J., Mitchell, A. J., Wales, J., \& Nielsen, S. (2011). Mortality rates in patients with anorexia nervosa and other eating disorders: A meta-analysis of 36 studies. Archives of General Psychiatry, 68(7), 724-731. http:/ /dx. doi.org/10.1001/archgenpsychiatry.2011.74
Assagioli, R. (2000). Psychosynthesis: A collection of basic writings. Amherst, MA: Synthesis.

Backholm, K., Isomaa, R., \& Birgegård, A. (2013). The prevalence and impact of trauma history in eating disorder patients. European Journal of Psychotraumatology, 4, 22482. http: / / dx.doi.org/ 10.3402 / ejpt.v4i0.22482

Brady, K. (2014). The role of stress, trauma, and PTSD in the etiology and treatment of eating disorders, addictions, and substance use disorders. In T. Brewerton \& A. Baker (Eds.), Eating disorders, addictions and substance use disorders: Research, clinical and treatment perspectives (pp. 379-404). New York, NY: Springer-Verlag.

Brewerton, T. (2015). Stress, trauma, and adversity as risk factors in the development of eating disorders. In L. Smolak \& M. Levine (Eds.), The Wiley handbook of eating disorders (1st ed.). New York, NY: John Wiley \& Sons.

Buber, M. (1971). I and thou. New York, NY: Simon and Schuster.

Cash, T. (2008). The body image workbook. Oakland, CA: New Harbinger Publications.

Catanzaro, J. (2016). IFS and eating disorders: Healing the parts who hide in plain sight. In M. Sweezy \& E. L. Ziskind (Eds.), Innovations and elaborations in internal family systems therapy (pp. 49-69). New York, NY: Routledge.

Cook-Cottone, C. (2016). Embodied self-regulation and mindful self-care in the prevention of eating disorders. Eating Disorders, 24(1), 98-105. http://dx.doi.org/10. $1080 / 10640266.2015 .1118954$

de Jong, M., Korrelboom, K., van der Meer, I., Deen, M., Hoek, H. W., \& Spinhoven, P. (2016). Effectiveness of enhanced cognitive behavioral therapy (CBT-E) for eating disorders: Study protocol for a randomized controlled trial. Trials, 17(1), 573. http:// dx.doi.org/10. 1186/s13063-016-1716-3

Dworkin, M., \& Errebo, N. (2010). Rupture and repair in the EMDR client/clinician relationship: Now moments and moments of meeting. Journal of EMDR Practice and Research, 4(3), 113-123. http://dx.doi.org/10.1891/ 1933-3196.4.3.113

Federn, P. (1952). Ego psychology and the psychoses. New York, NY: Basic Books.

Fichter, M. M., \& Quadflieg, N. (2016). Mortality in eating disorders - results of a large prospective clinical longitudinal study. International Journal of Eating Disorders, 49(4), 391-401. http: / / dx.doi.org/10.1002/ eat.22501

Forgash, C., \& Copeley, M. (Eds.). (2008). Healing the heart of trauma and dissociation with EMDR and ego state therapy. New York, NY: Springer Publishing.

Fraser, G. A. (2003). Fraser's "dissociative table technique” revisited, revised: A strategy for working with ego states in dissociative disorders and ego-state therapy. Journal of Trauma \& Dissociation, 4(4), 5-28. http: / / dx.doi.org/ 10. 1300/J229v04n04_02

Goulding, R., \& Schwartz, R. (2002). The mosaic mind. Oak Park, IL: Trailhead Publications. 
Hodges Chaffee, C., \& Kahm, A. (2015). Measuring health from the inside: Nutrition, metabolism and body composition. Victoria, BC, Canada: Friesen Press.

Juarascio, A., Shaw, J., Forman, E., Timko, C. A., Herbert, J., Butryn, M., . . . Lowe, M. (2013). Acceptance and commitment therapy as a novel treatment for eating disorders: An initial test of efficacy and mediation. Behavior Modification, 37(4), 459-489. http: / / dx.doi.org/ $10.1177 / 0145445513478633$

Knipe, J. (2015). EMDR tool box: Theory and treatment of complex PTSD and dissociation. New York, NY: Springer Publishing.

Kristeller, J., Wolever, R. Q., \& Sheets, V. (2014). Mindfulness-based eating awareness training (MB-EAT) for binge eating: A randomized clinical trial. Mindfulness, 5(3), 282-297. http: / / dx.doi.org/10.1007/s12671-012-0179-1

Lightstone, J. (2004). Dissociation and compulsive eating. Journal of Trauma \& Dissociation, 5(4), 17-32. http: / / dx. doi.org/10.1300/J229v05n04_02

Linardon, J., \& Brennan, L. (2017). The effects of cognitive-behavioral therapy for eating disorders on quality of life: A meta-analysis. International Journal of Eating Disorders, 50(7), 715-730. http://dx.doi.org/10.1002/ eat.22719

Maine, M., Hartmann McGilley, B., \& Bunnell, D. (Eds.). (2010). Treatment of eating disorders: Bridging the research-practice gap. Burlington, MA: Academic Press.

Martin, K. (2018). Conceptualizing trauma and eating disorders through the lens of structural dissociation theory. In A. Seubert \& P. Virdi (Eds.), Trauma-informed approaches to eating disorders. New York, NY: Springer Publishing.

Martz, D. M., \& Rogers, C. B. (2016). Understanding and treating women's body image and eating disorders. North Carolina Medical Journal, 77(6), 426-429. http: / / dx. doi.org/10.18043/ncm.77.6.426

Moulton, S. J., Newman, E., Power, K., Swanson, V., \& Day, K. (2015). Childhood trauma and eating psychopathology: A mediating role for dissociation and emotion dysregulation? Child Abuse \& Neglect, 39, 167-174. http: / / dx.doi.org/10.1016/j.chiabu.2014.07.003

Murphy, R., Straebler, S., Cooper, Z., \& Fairburn, C. G. (2010). Cognitive behavioral therapy for eating disorders. Psychiatric Clinics of North America, 33(3), 611-627. http: / / dx.doi.org/10.1016/j.psc.2010.04.004

O'Shea, K., \& Paulsen, S. (2015). When there are no words [workshop]. Retrieved from https: / /www.gifrinc.com/ course/when-there-are-no-words /

Pace, P. (2005). Lifespan integration: Connecting ego states through time (3rd ed.). Bellevue, NY: Author.

Palmisano, G. L., Innamorati, M., Susca, G., Traetta, D., Sarracino, D., \& Vanderlinden, J. (2017). Childhood traumatic experiences and dissociative phenomena in eating disorders: Level and association with the severity of binge eating symptoms. Journal of Trauma \& Dissociation, 19(1), 88-107. http://dx.doi.org/10.1080/ 15299732.2017 .1304490
Paulsen, S. (1995). Eye movement desensitization and reprocessing: Its cautious use in the dissociative disorders. Dissociation, 8, 32-44.

Paulsen, S. (2009). Looking through the eyes of trauma and dissociation. Charleston, SC: Booksurge.

Paulsen, S., \& Lanius, U. (2009). Toward an embodied self: Integrating EMDR with somatic and ego state interventions. In R. Shapiro (Ed.), EMDR Solutions II: For depression, eating disorders, performance and more (pp. 335-388). New York, NY: W. W. Norton.

Perls, F. (1969). Gestalt therapy verbatim. New York, NY: Bantam Books.

Polster, E., \& Polster, M. (1973). Gestalt therapy integrated. New York, NY: Vintage Books.

Ressler, A., Kleinman, S., \& Mott, E. (2010). The use of holistic methods to integrate the shattered self. In M. Maine, B. Hartmann McGilley, \& D. W. Bunnell (Eds.), Treatment of eating disorders: Bridging the research-practice gap (pp. 404-425). London, UK: Academic Press.

Schmidt, S. J. (2009). The developmental needs meeting strategy: An ego state psychotherapy for healing childhood wounds. San Antonio, TX: DNMS Institute.

Schwartz, R. (1995). Internal family systems therapy. New York, NY: Guilford Press.

Seijo, N. (2011, July). The "Rejected Self:" Treating defenses in eating disorders with EMDR. Presentation at the IX Congreso Nacional de Psicología Clínica, San Sebastián, Spain.

Seijo, N. (2016). The rejected self: Working with body image distortion in eating disorders. ESTD Newsletter, 5(4), 5-13. Retrieved from http://www.nataliaseijo. com/PDF/Rejectedself.pdf

Seubert, A. (2008). The courage to feel. Conshohocken, PA: Infinity.

Seubert, A. (2009). The case of mistaken identity: EMDR and ego state therapy in the treatment of eating disorders. Presentation at the 5th Western Mass EMDRIA Regional Network Spring Conference, Amherst, MA.

Seubert, A. (2014). Workshop: EMDR and ego state work: from essentials to advanced. Buffalo, NY.

Seubert, A. (2016, August). The girl in the mirror. Presentation at the EMDRIA International Conference, Minneapolis, MN.

Seubert, A., \& Virdi, P. (Eds.). (2018). Trauma-informed approaches to eating disorders. New York, NY: Springer Publishing.

Shapiro, F. (2018). Eye movement desensitization and reprocessing. New York, NY: Guilford Press.

Shapiro, R. (2016). Easy ego state interventions: Strategies for working with parts. New York, NY: W. W. Norton.

Smith, C. (1989-1992). Training: An existential-gestalt approach to psychotherapy. Warm Springs, PA.

Steele, A. (2007). Developing a secure self: An attachment-based approach to adult psychotherapy. Gabriola, BC, Canada: Author.

Stern, L. (2010). The slender trap: A food and body workbook. Pittsburgh, PA: Pin Thin Press. 
Substance Abuse and Mental Health Services Administration. (2014). SAMHSA's concept of trauma and guidance for a trauma-informed approach. HHS Publication No. (SMA) 14-4884. Rockville, MD: Author.

Tobin, S. (2004). The integration of relational Gestalt therapy and EMDR. International Gestalt Journal, 27(1), 55-82.

Twombly, J. (2005). EMDR for clients with dissociative identity disorder, DDNOS, and ego states. In R. Shapiro (Ed.), EMDR solutions (pp. 88-120). New York, NY: W. W. Norton. Utzinger, L. M., Haukebo, J. E., Simonich, H., Wonderlich, S. A., Cao, L., Lavender, J. M., . . Crosby, R. D. (2016). A latent profile analysis of childhood trauma in women with bulimia nervosa: Associations with borderline personality disorder psychopathology. International Journal of Eating Disorders, 49(7), 689-694. http://dx.doi.org/10.1002/ eat. 22532 van der Hart, O., Nijenhuis, E., \& Steele, K. (2006). The haunted self: Structural dissociation and the treatment of chronic traumatization. New York, NY: W.W. Norton.

van der Hart, O., Steele, K., Boon, S., \& Brown, P. (1993). The treatment of traumatic memories: Synthesis, realization, and integration. Dissociation, 6(2/3), 162-180.

Watkins, H., \& Watkins, J. (1997). Ego states: Theory and therapy. New York, NY: W. W. Norton.

Zinker, J. (1978). Creative process in Gestalt therapy. New York, NY: Random House.

Correspondence regarding this article should be directed to Andrew Seubert, LMHC, NCC, ClearPath Healing Arts Center, 3835 North Falls Road, Burdett, New York, NY 14818. E-mail: andrew@clearpathhealingarts.com; seuberta@mac.com 